\title{
Incidence of diabetes retinopathy and determinants of time to diabetes retinopathy among diabetes patients at Tikur Anbessa Hospital, Ethiopia: a retrospective follow up study
}

Tabot Keskis Azeze ${ }^{1}$, Malede Mequanent Sisay ${ }^{2 *}$ and Ejigu Gebeye Zeleke²

\begin{abstract}
Objective: Data regarding diabetes retinopathy and associated factors are currently lacking in Ethiopia. The study aims to determine the incidence and determinants of time to diabetes retinopathy among diabetes mellitus patients at Tikur Anbessa Specialized Hospital, Addis Ababa, Ethiopia.

Results: The incidence of diabetes retinopathy is a rapidly growing burden of disease in Ethiopia. The incidence rate of diabetes retinopathy was $2.65(95 \% \mathrm{Cl} 2.54,4.05)$ per 1000 person-years observation. Moreover, $70(18.57 \%, 95 \% \mathrm{Cl}$ $14.63,22.5)$ DM patients developed diabetes retinopathy. The median time was 74.07 months (with IQR 53.60, 89.88). Male sex $(A H R=1.94,95 \% C l=1.10,3.39)$, type $2 \mathrm{DM}(\mathrm{AHR}=4.01,95 \% \mathrm{Cl}=1.34,12.00)$, creatinine $(\mathrm{AHR}=2.59,95 \%$ $\mathrm{Cl}=1.91,3.52)$, borderline triglyceride $(\mathrm{AHR}=2.87,95 \% \mathrm{Cl} 1.33,6.21)$ and high triglyceride levels $(\mathrm{AHR}=2.59,95 \%$ $\mathrm{Cl}=1.31,4.97$ ) were positively correlated factors to diabetes retinopathy occurrence. Multisectoral, population-based approaches are needed to reduce type 2 DM complications.
\end{abstract}

Keywords: Complication of diabetes mellitus, Diabetes retinopathy, Ethiopia, Incidence, Determinants

\section{Introduction}

Diabetes mellitus (DM) is an important public health problem throughout the world and its prevalence has been steadily increasing over the past few decades [1]. Diabetes retinopathy (DR) is one of the life-threatening complications and is the most common cause of acquired blindness in adults [1-3].

Studies done in different countries showed that the incidence of DR was geographically heterogeneous, including in low and middle-income countries [4-15]. According to a systematic review, DR affects $30.2-31.6 \%$ of diabetes patients in Africa [16]. Specifically, the

\footnotetext{
*Correspondence: maledecsa@gmail.com

${ }^{2}$ Department of Epidemiology and Biostatistics, Institute of Public Health, College of Medicine and Health Sciences, University of Gondar, Gondar, Ethiopia

Full list of author information is available at the end of the article
}

prevalence of DR is growing most rapidly in Sub-Saharan Africa countries imposing a large economic burden on these countries [17-24].

The most common risk factors related to DR are sociodemographic characteristics such as age, sex, body mass index (BMI), hypertension, poor glycemic control, type 2 diabetes mellitus (T2DM), blood pressure (BP), cholesterol level and time since diabetes diagnosis [22, 2531 . However, the importance of the above factors varies between studies.

Several studies in Ethiopia have shown that the presence and severity of complications related to DR are steadily increasing cause of premature death and disability [19, 22, 32]. The incidence of DR has been well documented and risk factors are known in developed countries. However, studies regarding the incidence of related to diabetes retinopathy are scarce in Ethiopia and 
among the greater Africa continent in general. Therefore, the aim of this study was to identify the risk factors leading to DR among patients with diabetes at Tikur Anbessa specialized Hospital (TAH), Addis Ababa, Ethiopia.

\section{Main text Methods}

An institution-based retrospective follow up study was conducted at Tikur Anbessa Hospital, the largest referral public and teaching hospital in the country, located in the capital city of Ethiopia, Addis Ababa. The hospital receives approximately $370,000-400,000$ patients referred from across Ethiopia yearly [32]. The hospital has had an established diabetes clinic since 1994. Nearly 10,000 patients have enrolled the clinic due to diabetes related retinopathy disease and over 869 DM patients visited the hospital in 2017.

Patients newly diagnosed with type 1 or type $2 \mathrm{DM}$ from January 2009 to May 2017 were considered for this study. Those who had at least one follow up visit and adults (aged $\geq 15$ years) were included. The required sample size (373) was determined using a single population formula $n=\frac{Z_{\alpha / 2}^{2} * p(1-p)}{d^{2}}$, where $\mathrm{n}$ is the sample size; $\mathrm{z}$ is the value of standard normal distribution corresponding to a significant level of $\alpha$ of $5 \%$, which is 1.96 ; $\mathrm{d}$ is the margin of error which was taken as $5 \%$ and $\mathrm{p}$ is the estimated proportion of DR among diabetes patients $41.4 \%$ [33]. Data were collected by standard data extraction checklist, entered using Epi Info 7 and exported to STATA 14 software for analysis. The outcome variable was time to DR due to DM after dilated eye examination using tonometry and ophthalmologic instruments. Diabetic retinopathy diagnosis includes a medical history, an ophthalmic examination and screening with retinal photographs, and regular follow up. In short, diabetes retinopathy was defined by both direct and indirect ophthalmoscopy assessments done by retinal specialists confirmed by fundus photography. Diabetes retinopathy occurs when blood vessels in the retina and optic nerve are damaged using dilated eye exam (drops are placed in the eyes to widen or dilate the pupils) using a special magnifying lens. Diabetes retinopathy apparat if there is leaking blood in retinal vessels, Pale, fatty deposits on the retina indicating leaking blood vessels. The incidence of DR was determined from the start of diagnosis date of DM until the last follow-up visit or known date of DR occurrence.

We used Cox regression survival model, since time to DR is non-negative values often exhibiting highly skewed distributions and censors [34]. Variables in the bi-variable proportional hazard model with a p-value below $2 \%$ were subsequently included in the multivariable analysis.
The parsimonious model was selected using the log likelihood test and Akaike's information criterion (AIC). Schoenfeld residual and Cox-Snell residual plot were used to check the model's assumptions. The adjusted hazard ratio (AHR) with their respective 95\% confidence intervals (CI) were reported to show the strength of the associations.

\section{Results}

A total of 377 adult diabetes patients were included in the final analysis. Of these, 194 (51.5\%) were females and $315(83.6 \%)$ resided in Addis Ababa. The average age at initiation was 45 years $(\mathrm{SD} \pm 15.76)$. Approximately, 174 (47.7\%) had normal body mass index.

About 266 (70.6\%) of the study participants presented with type 2 DM and 263 (69.8\%) had no history of hypertension. More than half, 206 (54.6\%) were taking oral drug regimens for diabetes treatment. Furthermore, 151 (40\%) and 242 (64.2\%) had normal systolic and diastolic BPs, respectively. Nearly two-thirds, $252(66.8 \%)$ had very high fasting blood sugar and only 148 (45.5\%) had desirable triglyceride levels. The majority of the DM patients, 267 (82.2\%) had acceptable low-density lipoprotein levels. Whereas the median creatinine was $0.96 \mathrm{mg} / \mathrm{dl}$ (IQR 0.8-1.2) (Table 1).

From the total, $70(18.57 \%, 95 \%$ CI 14.63, 22.50) developed diabetes retinopathy. The incidence rate was 2.65 (95\% CI 2.54, 4.05) per 1000 adult-months observation with a total follow-up time of 26,384.9 adult-months observation. Moreover, the incidence rate was 21.4 and $11.7 \%$ among Type 2 and Type $1 \mathrm{DM}$, respectively.

The study participants were followed for a minimum of one and a maximum of 108 months after their initial DM diagnosis with 74 (IQR 53.60, 89.88) months median follow-up time.

From multivariable Weibull cox regression analysis, the expected hazard ratio of DR was 1.94 times higher in male DM patients than in female ones while keeping other covariates constant $(\mathrm{AHR}=1.94 ; 95 \%$ CI 1.10 , 3.39). Furthermore, when the baseline creatinine level of $\mathrm{DM}$ patients increased by a single $\mathrm{mg} / \mathrm{dl}$, the hazard ratio of developing DR increased by 1.78 (AHR $=1.78: 95 \% \mathrm{CI}$; $1.58,2.01)$. High triglyceride levels among patients with DM increases their likelihood developing DR by 2.59 than those who have desirable triglyceride levels $(\mathrm{AHR}=2.59$, $95 \%$ CI 1.33, 6.21). Similarly, the expected hazard ratio of DR was 2.87 times higher among DM patients who had borderline high triglycerides compared to DM patients who had desirable triglyceride levels $(A H R=2.87 ; 95 \%$ CI 1.31, 4.97). In regards to complication status, patients with type $2 \mathrm{DM}$ are 4 times more likely to develop DR compared to type $1 \mathrm{DM}$ patients $(\mathrm{AHR}=4.01 ; 95 \% \mathrm{CI}$ $1.34,12.0$ ) (Table 2). 
Table 1 Demographic, clinical and physiological characteristics of DM patients at Tikur Anbessa Hospital, Addis Ababa, Ethiopia, 2009-2017

\begin{tabular}{|c|c|c|c|c|c|}
\hline Variables & Category & DR & Censored & Frequency & Percent \\
\hline \multirow[t]{2}{*}{ Type of DM } & Type 1 & 13 & 98 & 111 & 29.4 \\
\hline & Type 2 & 57 & 209 & 266 & 70.6 \\
\hline \multirow[t]{2}{*}{ Sex } & Male & 26 & 157 & 183 & 48.5 \\
\hline & Female & 44 & 144 & 194 & 51.5 \\
\hline \multirow[t]{2}{*}{ Residence } & Addis Ababa & 59 & 256 & 315 & 83.6 \\
\hline & Out of Addis Ababa & 11 & 51 & 62 & 16.4 \\
\hline \multirow[t]{4}{*}{ BMI } & Underweight & 5 & 35 & 40 & 11 \\
\hline & Normal & 35 & 139 & 174 & 47.7 \\
\hline & Overweight & 16 & 90 & 106 & 29 \\
\hline & Obese & 10 & 35 & 45 & 12.3 \\
\hline \multirow[t]{2}{*}{ Regimen of DM } & Insulin & 29 & 142 & 171 & 45.4 \\
\hline & Oral & 41 & 165 & 206 & 54.6 \\
\hline \multirow[t]{2}{*}{ Hypertension } & Yes & 25 & 89 & 114 & 30.2 \\
\hline & No & 45 & 218 & 263 & 69.8 \\
\hline \multirow[t]{3}{*}{ Systolic BP (mmHg) } & $\leq 110$ & 19 & 105 & 124 & 32.9 \\
\hline & $110-130$ & 30 & 121 & 151 & 40 \\
\hline & $\geq 130$ & 21 & 81 & 102 & 27.1 \\
\hline \multirow[t]{3}{*}{ Diastolic BP (mmHg) } & $\leq 60$ & 12 & 51 & 63 & 16.7 \\
\hline & $60-80$ & 48 & 194 & 242 & 64.2 \\
\hline & $\geq 80$ & 10 & 62 & 72 & 19.1 \\
\hline \multirow[t]{4}{*}{ Fasting blood sugar (mg/dl) } & $<70$ & 5 & 10 & 15 & 4 \\
\hline & $70-100$ & 9 & 30 & 39 & 10.3 \\
\hline & $100-125$ & 13 & 57 & 70 & 18.8 \\
\hline & $\geq 126$ & 46 & 206 & 252 & 66.8 \\
\hline \multirow[t]{3}{*}{ Total cholesterol (mg/dl) } & $<200$ & 37 & 163 & 200 & 61.5 \\
\hline & $200-239$ & 10 & 36 & 69 & 21.2 \\
\hline & $>240$ & 20 & 36 & 56 & 17.3 \\
\hline \multirow[t]{3}{*}{ Triglyceride (mg/dl) } & $<150$ & 23 & 125 & 148 & 45.5 \\
\hline & $150-199$ & 12 & 38 & 50 & 16.5 \\
\hline & $\geq 200$ & 32 & 95 & 127 & 39.1 \\
\hline \multirow[t]{3}{*}{ Low density lipoprotein (mg/dl) } & $<150$ & 52 & 215 & 267 & 82.2 \\
\hline & $150-190$ & 2 & 13 & 15 & 4.6 \\
\hline & $\geq 190$ & 13 & 30 & 43 & 13.2 \\
\hline \multirow[t]{3}{*}{ High density lipoprotein (mg/dl) } & $\leq 40$ & 28 & 98 & 126 & 38.8 \\
\hline & $41-59$ & 26 & 100 & 126 & 38.8 \\
\hline & $\geq 60$ & 13 & 60 & 73 & 22.4 \\
\hline
\end{tabular}

\section{Discussion}

This study attempted to determine the incidence of diabetes retinopathy and the risk factors among DM patients at Tikur Anbessa specialized hospital, Addis Ababa, Ethiopia. The proportion of DR was $18.57 \%$ with 2.65 per 1000 adult-months observation. The study showed a higher incidence of DR than studies done in Bangladesh and China $[13,29]$. This inconsistency might be due to the difference in health care systems and the quality of care given to diabetes patients. However, the incidence rate in this study was lower than that of a study done at Arbaminch general hospital, Ethiopia [35]. This difference might also be due to the data collection period included in the study. Our study included 9 years of follow up data, whereas the Arba Minch study used 3 years follow up data. Moreover, has been a general health care improvement in Ethiopia recently [36].

The study identified that among DM patient's males had a shorter time than females to develop diabetes retinopathy. This result is in line with that of a study conducted in 


\begin{tabular}{|c|c|c|c|}
\hline Variables & Category & CHR $[95 \% \mathrm{Cl}]$ & AHR [95\% Cl] \\
\hline Age & & $1.02(1.012,1.03)$ & $0.99(0.97,1.02)$ \\
\hline Creatinine & & $1.78(1.58,2.01)$ & $2.59(1.91,3.52)$ \\
\hline \multirow[t]{2}{*}{ Sex } & Female & 1 & 1 \\
\hline & Male & $1.79(1.35,2.38)$ & $1.94(1.10,3.39)$ \\
\hline \multirow[t]{2}{*}{ Type of DM } & Type 1 & 1 & 1 \\
\hline & Type 2 & $2.71(1.9,3.86)$ & $4.01(1.34,12.00)$ \\
\hline \multirow[t]{3}{*}{ Systolic BP } & Normal & 1 & 1 \\
\hline & Low & $0.67(0.47,0.93)$ & $0.98(0.52,1.94)$ \\
\hline & High & $1.06(0.78,1.47)$ & $0.66(0.35,1.23)$ \\
\hline \multirow[t]{4}{*}{ Fasting blood sugar } & Normal & 1 & 1 \\
\hline & Нypo & $0.27(0.08,0.91)$ & $0.15(0.10,0.51)$ \\
\hline & High & $0.99(0.6,1.63)$ & $0.59(0.24,1.48)$ \\
\hline & Very high & $0.91(0.59,1.37)$ & $0.62(0.29,1.30)$ \\
\hline \multirow[t]{3}{*}{ Cholesterol status } & Desirable & 1 & 1 \\
\hline & High & $0.83(0.55,1.25)$ & $0.93(0.44,1.97)$ \\
\hline & Very high & $2.39(1.74,3.29)$ & $1.55(0.76,3.21)$ \\
\hline \multirow[t]{3}{*}{ Triglycerides } & Desirable & 1 & 1 \\
\hline & Borderline & $2.25(1.49,3.39)$ & $2.87(1.33,6.21)$ \\
\hline & High & $2.28(2.04,3.86)$ & $2.59(1.31,4.97)$ \\
\hline \multirow{3}{*}{$\begin{array}{l}\text { Low-density lipo- } \\
\text { protein }\end{array}$} & Desirable & 1 & 1 \\
\hline & Borderline high & $1.5(1.07,2.19)$ & $1.78(0.83,3.82)$ \\
\hline & High & $0.73(0.32,1.66)$ & $0.64(0.14,2.93)$ \\
\hline \multirow[t]{2}{*}{ DM regimen } & Insulin & 1 & 1 \\
\hline & Oral & $1.55(1.18,2.06)$ & $0.71(0.39,1.29)$ \\
\hline \multirow[t]{2}{*}{ Hypertension } & No & 1 & 1 \\
\hline & Yes & $1.43(0.88,2.34)$ & $1.51(0.48,4.74)$ \\
\hline
\end{tabular}

China $[29,37]$. This might be due to the fact that neuroretinal function is more abnormal in adult males than in adult females [38]. However, a study conducted in Ethiopia [39] showed that males had a lower risk of developing microvascular complications of DM than females.

This study showed that the hazard of diabetes retinopathy was increased with increasing creatinine levels. This result is similar to that of a study done in New Zealand $[40,41]$. One reason for this may be that increasing creatinine values may decrease retinal fiber layer thickness [42].

The risk of developing DR among Type 2 DM patients was higher than among Type $1 \mathrm{DM}$ patients in this study. The result is similar to the study conducted at Ayder referral hospital in Ethiopia and noted that type $2 \mathrm{DM}$ patients had a shorter time to developing microvascular DM complications than Type 1 DM patients [39]. This may be due to the older age of most of the Type 2 patients and their inability to support themselves to receive appropriate eye screening services [43]. Furthermore, since the disease process of Type $2 \mathrm{DM}$ is more gradual than Type $1 \mathrm{DM}$, these patients may seek health services later in the disease course. In contrast, a study conducted in Spain found that type 1 diabetes patients had a higher risk to develop DR than type 2 [44]. The most likely explanation for this difference may relate to the study design, shorter follow-up period or smaller sample size as well as early screening.

The result in this study indicated that DM patients who had borderline high (150-199 mg/dl) and high (200$499 \mathrm{mg} / \mathrm{dl}$ ) triglyceride (TG) levels had a lower likelihood of DR than DM patients who had desirable $(<150 \mathrm{mg} / \mathrm{dl})$ TG level. This finding is consistent with the study findings in France [45] and Birmingham [46]. This is because raised TG levels increase blood viscosity, which in turn leads to the formation of hard exudates. In addition, TG incorporates into the cell membrane, altering its fluidity and permeability which ultimately may results in hemorrhages [47].

\section{Conclusion}

The incidence rate of diabetes retinopathy remains a high public health concern as the median time to developing diabetes retinopathy was relatively short. Health care workers should bear in mind that in addition to using drugs, consistent and proper triglyceride and creatinine level monitoring, as well as early screening and treatment of diabetes complications would be an essential part of DM care and delaying the onset of DR.

\section{Limitations}

One of the major limitations of the current study is the absence of institutional and behavioral factors, which may underestimate the effects and individual variations in the development of diabetes retinopathy. Secondly, Even though the study was conducted in the largest national referral center in which many adults come from around the country for DM follow up, the findings could not be representative of the adult diabetes population in the country due to possible selection bias.

Because of the retrospective nature of the study, some important complications of diabetes that had a significant association with DR, like chronic kidney disease were missed since we used chart review to obtain the data.

\section{Abbreviations}

AIC: Akaike's information criterion; BMI: body mass index; Cox-PH: Cox-proportional hazard; DBP: diastolic blood pressure; DR: diabetes retinopathy; DM: diabetes mellitus; DME: diabetes mellitus edema; HbA1c: glycated hemoglobina1 c; HDL: high-density lipid profile; HR: hazard ratios; LDL: low-density lipid profile; NPDR: non-proliferative diabetes retinopathy; PDR: proliferative diabetes retinopathy; SBP: systolic blood pressure; TAH:Tikur Anbessa Hospital; TC: total cholesterol; TG: triglyceride; IDF: International Diabetes Federation; 
VEGF: vascular endothelial growth factor; VTDR: vision-threatening diabetes retinopathy; WESDR: Wisconsin Epidemiological Study of Diabetes Retinopathy; WHO: World Health Organization.

\section{Authors' contributions}

All authors equally contributed to conceive and design the study. TKA participated in data collection and analysis as well as draft report. EGZ and MMS had also contributed to acquisition of data, analysis and interpretation of data. TKA, MMS and EGZ were involved in drafiting and revised it critically the manuscript contents. All authors read and approved the final manuscript.

\section{Author details}

${ }^{1}$ Ethiopian Postal Service Enterprise, Addis Ababa, Ethiopia. ${ }^{2}$ Department of Epidemiology and Biostatistics, Institute of Public Health, College of Medicine and Health Sciences, University of Gondar, Gondar, Ethiopia.

\section{Acknowledgements}

The authors express their appreciation to Tikur Anbessa Hospital, particularly the DM clinic staff for their kind cooperation during data collection. The authors are also grateful to the data collectors.

\section{Competing interests}

The authors declare that they have no competing interests.

\section{Availability of data and materials}

All data in this study are included in the manuscript. However, the minimal data are available from the authors upon reasonable request.

\section{Consent for publication}

Not applicable.

\section{Ethics approval and consent to participate}

Before the commencement of the study, ethical clearance was obtained from the Institutional Review Board of the University of Gondar. Then, permission letters from officials of Tikur Anbessa Hospital, Department of Internal Medicine were processed before data collection. To ensure confidentiality, patient names were not included, instead, code numbers were assigned to depict the results, and the anonymous data extraction tool was kept locked in a file cabinet.

\section{Funding}

The authors disclose receipt of the following financial support for the research, authorship, and/or publication of this article: This research was self-sponsored.

\section{Publisher's Note}

Springer Nature remains neutral with regard to jurisdictional claims in published maps and institutional affiliations.

Received: 22 June 2018 Accepted: 27 July 2018

Published online: 02 August 2018

\section{References}

1. World Health Organization. Global report on Diabetes. Geneva: World Health Organization; 2016.

2. Bourne RRA, et al. Causes of vision loss worldwide, 1990-2010: a systematic analysis. Lancet Glob Health. 2013. https://doi.org/10.1016/S2214 -109X(13)70113-X.

3. Klein BE. Overview of epidemiologic studies of diabetic retinopathy. Ophthal Epidemiol. 2007:14(4):179-83.

4. Hall V, Thomsen RW, Henriksen O, Lohse N. Diabetes in sub Saharan Africa 1999-2011: epidemiology and public health implications. A systematic review. BMC Public Health. 2011;1 1(1):564.

5. Worku D, Hamza L, Woldemichael K. Patterns of diabetic complications at Jimma university specialized hospital, Southwest Ethiopia. Ethiop J Health Sci. 2010;20(1):33-9.

6. Alemu S, Dessie A, Tsegaw A, Patterson CC, Parry EH, Phillips DI, Trimble ER. Retinopathy in type 1 diabetes mellitus: Major differences between rural and urban dwellers in northwest Ethiopia. Diabetes Res Clin Pract. 2015;109(1):191-8.

7. Martino $\mathrm{E}$, et al. Incidence of retinal complications in a cohort of newly diagnosed diabetic patients. PLOS ONE. 2014;9(6):e100283.

8. Klein R, Klein KB, Moss SE, Cruickshanks KJ. The Wisconsin Epidemiologic Study of Diabetic Retinopathy XV: the long-term incidence of macular edema. Am Acad Ophthalmol. 1995;102(1):7-16.

9. Klein R, Knudston MD, Lee KE, Gangnon R, Klein BE. The Wisconsin epidemiologic study of diabetic retinopathy XXII: the twenty-five-year progression of retinopathy with type 1 diabetes. Ophthalmology. 2008;115(11):1859-68.

10. Thomas RL, Dunstan F, Luzio SD, Chowdury SR, Hale SL, North RV, Gibbins RL, Owens DR. Incidence of diabetic retinopathy in people with type 2 diabetes mellitus attending the Diabetic Retinopathy Screening Service for Wales: retrospective analysis. BMJ. 2011;344:874.

11. Jones CD, Greenwood RH, Misra A, Bachmann MO. Incidence and progression of diabetic retinopathy during 17 years of population-based screening program in England. Am Diabetes Assoc. 2012;35(3):592-6.

12. Salinero-Fort MÁ, San Andrés-Rebollo FJ, de Burgos-Lunar C, ArrietaBlanco FJ, Gómez-Campelo P, MADIABETES Group. Four-year incidence of diabetic retinopathy in a Spanish cohort: the MADIABETES study. PLoS ONE. 2013;8(10):e76417.

13. Hussain A, Ali L. Incidence of diabetic retinopathy: a 15 year follow up in a hospital population (Bangladesh). 2009.

14. Tung TH, Chen SJ, Liu JH, Lee FL, Li AF, Shyong MP, Chou P. A communitybased follow-up study on diabetic retinopathy among type 2 diabetics in Kinmen. Eur J Epidemiol. 2005;20(7):317-23.

15. Yau JW, et al. Global prevalence and major risk factors of diabetic retinopathy. Diabetes Care. 2012;35(3):556-64.

16. Burgess $\mathrm{Pl}$, et al. Epidemiology of diabetic retinopathy and maculopathy in Africa: a systematic review. Diabet Med. 2013;30:399-412.

17. Burgess Pl, Harding SP, García-Fiñana M, Beare NA, Msukwa G, Allain TJ. First prospective cohort study of diabetic retinopathy from Sub-Saharan Africa. Am Acad Ophthalmol. 2016;123(9):1919-25.

18. Hall V, et al. Diabetes in Sub Saharan Africa Epidemiology and public health implications. A systematic review. BMC Public Health. 2011;11:564.

19. Joint PG. Ethiopia Lion's Ethiopian ophthalmic programme against retinal disease and diabetes project. https://www.retinopathyscreening.co.uk. 2014.

20. Kahan HA, Hiller R. Blindness caused by diabetic retinopathy. Am Acad Ophthalmol. 1974;78:58-67.

21. Palmberg PF. Diabetic retinopathy. Diabetes Res Clin Pract. 1977;26(7):703-7.

22. Thhomas RL, Distiller L, Luzio SD, Melville VJ, Roy Chowdhury S, Kramer B, Owens DR. Incidence and Progression of diabetic retinopathy with in a private diabetes mellitus clinic in South Africa. J Endocrinol. 2015;20(3):127-33.

23. Gonder JR, Walker VM, Barbeau M, Zaour N, Zachau BH, Hartje JR, Li R. Costs and quality of life in diabetic macular edema: canadian burden of diabetic macular edema observational study (C-REALITY). J Ophthalmol. 2014;2014:939315. https://doi.org/10.1155/2014/939315.

24. Zheng Y, He M, Congdon N. The worldwide epidemic of diabetic retinopathy. Indian J Ophthalmol. 2012;60(5):428.

25. Hletala K, Harjutsalo V, Forsblom C, Groop PH. Age at onset and the risk of proliferative retinopathy in type 1 diabetes. Diabetes Care. 2010;36(6):1315-9.

26. Wang SY, Andrews CA, Herman WH, Gardner TW, Stein JD. Incidence and risk factors for developing diabetic retinopathy among youths with type 1 or type 2 diabetes throughout the United States. Am Acad Ophthalmol. 2016;146:424-30

27. Sandinha MT, Morphis G, Broadbent DM. Survival rates of patients undergoing vitrectomy for proliferative diabetic retinopathy. J Ophthalmol Vis Neurosci. 2016;1:2.

28. Leese GP, Stratton IM, Land M, Bachmann MO, Jones C, Scanlon P, Looker HC, Ferguson B, Four Nations Diabetic Retinopathy Screening Study Group. Progression of diabetes retinal status within community screening programs and potential implications for screening intervals. Diabetes Care. 2015;38:DC_141778.

29. Liu L, Wu J, Yue S, Geng J, Lian J, Teng W, Huang D, Chen L. Incidence density and risk factors of diabetic retinopathy within type 2 diabetes: 
a five-year cohort study in China. Int J Environ Res Public Health. 2015;12:7899-909.

30. Nwanyanwu KH, et al. Predicting development of proliferative diabetic retinopathy. Diabetes Care. 2013;36:dc 12-0790.

31. Tseng ST, Chou ST, Low BH, Su FL. Risk factors associated with diabetic retinopathy onset and progression in diabetes patients: a Taiwanese cohort study. Int J Clin Exp Med. 2015;8:21507.

32. AMECA. Alex's Medical and educational clinic in Africa. Ethiopia: Black Lion Specialized Hospital, AMECA; 2015.

33. Sharew $\mathrm{G}$, et al. Prevalence of diabetic retinopathy in Jimma University Hospital, Southwest Ethiopia. Ethiop Med J. 2013;51(2):105-13.

34. Hosmer DW. Applied survival analysis regression modeling of time to event data. Hoboken: Wiley; 1999.

35. Chisha Y, Terefe W, Assefa H. Incidence and factors associated with diabetic retinopathy among diabetes patients at Arba Minch general hospital. J Diabetol. 2017;8(1):1.

36. Central Statistical Agency (CSA) [Ethiopia], ICF Macro. Ethiopia demographic and health survey 2011. Calverton; Addis Ababa: Central Statistical Agency and ICF Macro; 2011.

37. Ozawa GY, Bearse MA. Adams AJ Male-female differences in diabetic retinopathy. Curr Eye Res. 2015;40(2):234-46.

38. Ozawa GY, Bearse MA Jr. Male-female differences in diabetic retinopathy. Invest Ophthalmol Vis Sci. 2015;53(6).

39. Berihun L, Muluneh EK. Correlates of time to microvascular complications among diabetes mellitus patients using parametric and non-parametric approaches: a case study of Ayder referral hospital, Ethiopia. Ethiop J Sci Technol. 2017;10(1):65-80.

40. Kim BZ, Lee KL, Guest SJ, Worsley D. Long-term survival following diabetic vitrectomy. Hypertension. 2017;155:85-92.

41. Larsen $M B$, et al. Prevalence and risk factors for diabetic retinopathy in 17152 patients from the island of Funen, Denmark. Acta Ophthalmol. 2017;95:778-86.

42. Srivastav K, et al. Increased serum urea and creatinine levels correlate with decreased retinal nerve fibre layer thickness in diabetic retinopathy. Biomarkers. 2015;20(6-7):470-3. https://doi.org/10.3109/1354750X.2015.

43. Wong TY, Cheung CM, Larsen M, Sharma S, Simó R. Diabetic retinopathy. Nat Rev Dis Primers. 2016;2:16012. https://doi.org/10.1038/nrdp.2016.12.

44. Romero-Aroca P. Differences in incidence of diabetic retinopathy between type 1 and 2 diabetes mellitus: a nine-year follow-up study. Br J ophthalmol. 2017. https://doi.org/10.1136/bjophthalmol.

45. Hadjadj S, Duly-Bouhanick B, Bekherraz A, Br Idoux F, Gallois Y, Mauco G, Ebran JM, Marre M. Serum triglycerides are a predictive factor for the development and the progression of renal and retinal complications in patients with type 1 diabetes. Diabetes Metab. 2004;30(1):43-51.

46. Wright AD, Dodson PM. Medical management of diabetic retinopathy: fenofibrate and ACCORD Eye studies. Eye (Lond). 2011;25(7):843-9. https //doi.org/10.1038/eye.2011.62.

47. Mathur A, Mathur R. Study of association of serum lipids with diabetic retinopathy in type 2 diabetes mellitus. J Sci Res. 2013;6(1):94-7.
Ready to submit your research? Choose BMC and benefit from:

- fast, convenient online submission

- thorough peer review by experienced researchers in your field

- rapid publication on acceptance

- support for research data, including large and complex data types

- gold Open Access which fosters wider collaboration and increased citations

- maximum visibility for your research: over 100M website views per year

At BMC, research is always in progress.

Learn more biomedcentral.com/submissions 